\title{
22q11.2 Deletion syndrome is associated with perioperative outcome in tetralogy of Fallot
}

\author{
Laura Mercer-Rosa, MD, MSCE, ${ }^{\mathrm{a}}$ Nelangi Pinto, MD, ${ }^{\mathrm{b}}$ Wei Yang, $\mathrm{PhD},{ }^{\mathrm{c}}$ Ronn Tanel, MD, ${ }^{\mathrm{d}}$ and \\ Elizabeth Goldmuntz, MD ${ }^{\mathrm{a}}$
}

Objective: We sought to investigate the impact of 22q11.2 deletion on perioperative outcome in tetralogy of Fallot.

\begin{abstract}
Methods: We conducted a retrospective review of patients with tetralogy of Fallot who underwent complete surgical reconstruction at The Children's Hospital of Philadelphia between 1995 and 2006. Inclusion criteria included diagnosis of tetralogy of Fallot and known genotype. Fisher exact and Mann-Whitney tests were used for categoric and continuous variables, respectively. Regression analysis was used to determine whether deletion status predicts outcome.
\end{abstract}

\begin{abstract}
Results: We studied 208 subjects with tetralogy of Fallot, 164 (79\%) without and 44 (20\%) with 22q11.2 deletion syndrome. There were no differences in sex, race, gestational age, age at diagnosis, admission weight, and duration of mechanical ventilation. Presenting anatomy, survival, complications and reoperations were also comparable between patients with and without 22q11.2 deletion syndrome. Those with 22q11.2 deletion syndrome had more aortopulmonary shunts preceding complete surgical repair $(21 \%$ vs $7 \%, P=.02)$. This association was present after adjustment for presenting anatomy (stenosis, atresia, or absence of pulmonary valve and common atrioventricular canal) and surgical era. In addition, those with 22q11.2 deletion syndrome had longer cardiopulmonary bypass time ( 84 vs 72 minutes, $P=.02$ ) and duration of intensive care (6 vs 4 days, $P=.007)$.
\end{abstract}

Conclusions: Genotype affects early operative outcomes in tetralogy of Fallot resulting, in particular, in longer duration of intensive care. Future studies are required to determine factors contributing to such differences in this susceptible population. (J Thorac Cardiovasc Surg 2013;146:868-73)

Tetralogy of Fallot (TOF) is the most common cyanotic congenital heart disease, comprising up to $7 \%$ of all cardiac defects. ${ }^{1}$ It is commonly associated with genetic syndromes, particularly the 22q11.2 deletion syndrome (22q11.2DS), which is present in $15 \%$ to $20 \%$ of patients with $\mathrm{TOF}^{2-5}$ The presence of a genetic syndrome has been associated with increased morbidity and mortality in TOF; however, the underlying mechanisms remain to be

From the Division of Cardiology, ${ }^{\mathrm{a}}$ Department of Pediatrics, The Children's Hospital of Philadelphia and the University of Pennsylvania Perelman School of Medicine, Philadelphia, Pa; Division of Cardiology, ${ }^{\mathrm{b}}$ Department of Pediatrics, Primary Children's Medical Center, University of Utah School of Medicine, Salt Lake City, Utah; Center for Clinical Epidemiology and Biostatistics, ${ }^{\mathrm{c}}$ Perelman School of Medicine, University of Pennsylvania, Philadelphia, Pa; and Division of Pediatric Cardiology, ${ }^{\mathrm{d}}$ UCSF Benioff Children's Hospital, Department of Pediatrics, University of California San Francisco School of Medicine, San Francisco, Calif.

This work was supported by the National Institutes of Health (P50-HL74731 and 5T32HL007915).

Disclosures: Dr Tanel has grants from Medtronic and St Jude Medical, Inc, for fellow training and has previously served on a speaker's bureau for St Jude Medical Inc. The other authors have nothing to disclose with regard to commercial support.

Received for publication July 25, 2012; revisions received Nov 1, 2012; accepted for publication Dec 10, 2012; available ahead of print Jan 14, 2013.

Address for reprints: Laura Mercer-Rosa, MD, MSCE, Division of Cardiology, The Children's Hospital of Philadelphia, 34th and Civic Center Blvd, Suite 8NW35, Philadelphia, PA 19104 (E-mail: mercerrosal@email.chop.edu).

0022-5223/\$36.00

Copyright (c) 2013 by The American Association for Thoracic Surgery

http://dx.doi.org/10.1016/j.jtcvs.2012.12.028 identified and may vary by genotype. ${ }^{6}$ For example, increased mortality in the TOF subset with pulmonary atresia and 22q11.2DS is seen irrespective of the degree of pulmonary artery hypoplasia. ${ }^{7}$ In addition, noncardiac abnormalities and malformation syndromes appear to be independent risk factors for prolonged intubation, reintubation, and longer intensive care duration. ${ }^{8,9}$ Therefore, factors related to genotype influence outcomes.

Risk stratification and counseling of patients with 22q11.2DS are of paramount importance in an era of prenatal diagnosis, advanced perinatal intensive care, and access to subspecialized medicine. Understanding how genotype affects outcomes might guide surgical decisions, perioperative care, and pre- and postnatal counseling. In addition, this knowledge may allow us to optimize management, consequently leading to shorter hospital stays and improved cardiovascular and neurocognitive outcomes.

We therefore sought to investigate the association of 22q11.2DS and perioperative outcomes in patients with TOF.

\section{MATERIALS AND METHODS Study Population}

The study protocol was approved by the Institutional Review Board for the Protection of Human Subjects at The Children's Hospital of Philadelphia. We conducted a retrospective chart review study of patients who 


$$
\begin{array}{ll}
\text { Abbreviations and Acronyms } \\
\begin{array}{ll}
\text { CPB } & =\text { cardiopulmonary bypass } \\
\mathrm{ND} & =\text { nondeleted } \\
\mathrm{RV} & =\text { right ventricular } \\
\mathrm{TOF} & =\text { tetralogy of Fallot } \\
22 \mathrm{q} 11.2 \mathrm{DS} & =22 \mathrm{q} 11.2 \text { deletion syndrome } \\
\mathrm{VSD} & =\text { ventricular septal defect }
\end{array}
\end{array}
$$

underwent surgical repair for TOF at The Children's Hospital of Philadelphia between 1995 and 2006. We included patients who underwent complete surgical reconstruction for TOF in a single operation, whether or not it was preceded by placement of an aortopulmonary shunt. Patients who underwent multiple stages of operations to reach complete repair and those with genetic syndromes other than 22q11.2DS (eg, trisomy 21 and Alagille syndrome) were excluded. The hospital's cardiothoracic surgical database was used for subject ascertainment. Deletion status was confirmed for all patients. All patients with 22q11.2DS were included. All nondeleted (ND) subjects with TOF and pulmonary valve atresia, absent pulmonary valve leaflets, and associated common atrioventricular canal were included. A subset of ND subjects with TOF and pulmonary valve stenosis were randomly selected for comparative chart review based on a power analysis that determined the sample size of TOF with pulmonary stenosis needed for comparison with the 22q11.2DS group to detect differences in length of hospital stay. Surgical repair was categorized as (1) closure of ventricular septal defect (VSD) without need for relief of right ventricular (RV) outflow tract obstruction; (2) VSD closure and relief of $\mathrm{RV}$ outflow tract obstruction with placement of a patch without crossing the pulmonary valve annulus (nontransannular patch); (3) VSD closure and relief of RV outflow tract obstruction with placement of a patch crossing the pulmonary valve annulus (transannular patch); and (4) VSD closure and placement of an RV to pulmonary artery conduit. Surgical era was divided between early (1995-2000) and late (2001-2006) time periods.

\section{Data Collection}

Hospital medical records were reviewed to abstract the demographic and relevant clinical variables from the index hospitalization. Intensive care was defined as the time between postoperative admission to the cardiac intensive care unit to the time of discontinuation of mechanical ventilation, removal of chest tubes and intracardiac lines, and discontinuation of vasopressor medications. Subjects were grouped according to deletion status. Anatomy was divided according to the pulmonary valve morphology: stenosis, atresia, absent leaflets, and TOF with complete common atrioventricular canal defect. Major congenital anomalies (eg, cleft palate, intestinal malrotation, tracheoesophageal fistula) were recorded. Operative and perioperative variables were collected, including cardiopulmonary bypass (CPB) duration, cardiac and noncardiac events, discharge status (feeding method), and number of medications. Examples of noncardiac events included number of consulting services, infections requiring antibiotic treatment, postoperative seizures confirmed by electroencephalogram, pleural effusions requiring drainage, and tracheostomy. Examples of cardiac events included pericardial effusions requiring pericardiocentesis, arrhythmias requiring treatment, postoperative cardiac catheterizations, reoperations, and cardiac arrest requiring resuscitation.

\section{Statistical Analysis}

Continuous variables were described as mean and standard deviation or as median with interquartile ranges, where appropriate. Frequencies with proportions were reported for categoric variables. The differences between deleted and nondeleted groups were tested with the Wilcoxon rank-sum test for continuous variables and the Fisher exact test for categoric variables.
Multivariable regression models were used to assess the independent associations between deletion status and length of intensive care, palliative procedure, and CPB time, adjusting for potential confounders, including birth weight, age at repair, gestational age, and pulmonary valve status. $P$ values were 2-sided. All analyses were performed using SAS software version 9.2 (SAS Institute, Inc, Cary, NC).

\section{RESULTS}

\section{General Characteristics}

The study included 208 subjects who met eligibility criteria. A total of $164 \mathrm{ND}$ patients were included for comparison with 44 patients who had confirmed 22q11.2DS. Analysis limited to survivors did not affect the comparisons between the 2 groups; therefore, we included survivors and nonsurvivors in the results. We found a predominance of male subjects $(60 \%)$ and whites $(76 \%)$. Most were born full term $(79 \%)$ and were diagnosed postnatally $(71 \%)$ (Table 1). Pulmonary valve stenosis was the most common presenting pulmonary valve status $(63 \%)$. Ten percent of subjects received an aortopulmonary shunt preceding complete repair. Most subjects underwent surgery before 6 months of age, with $30 \%$ in the neonatal period. Relief of RV outflow tract obstruction was achieved with a transannular patch in $60 \%$ of subjects (Table 1 ).

\section{Comparisons According to Genotype}

Subjects with and without 22q11.2DS were comparable in terms of gender, race, weight, gestational age, timing of diagnosis, presenting pulmonary valve status, and age at surgical repair. In addition, there was no difference in frequency of neonatal repairs (Table 1). A total of 22 aortopulmonary shunts preceded complete repair, 12 performed in the early surgical era and 10 in the late era $(P=.37)$.

Four patients died (3 ND and 1 22q11.2DS). There was no difference in mortality between the 2 groups $(P=1.0)$. Most patients were discharged directly home, with a minority being transferred to other facilities for continuation of care (Table 2).

The 22q11.2DS and ND groups were comparable in terms of duration of time in the hospital preceding operation, length of stay after discharge from the intensive care unit, duration of mechanical ventilation, number of cardiac and noncardiac complications, and number of reoperations (Table 2). There was a trend for longer overall length of hospital stay in the 22q11.2DS group $(P=.053)$. Feeding status at discharge and the number of infections in the hospital were comparable between the 2 groups $(P=.11$ and .21 , respectively).

Major congenital anomalies were found in both groups, without significant difference by deletion status. As expected for this patient population, those with 22q11.2DS had more dysmorphic facies and more frequent ear, nose, mouth, palate, hand, and skeletal anomalies. Other organ systems were equally affected in the 2 subgroups. 
TABLE 1. Patient characteristics

\begin{tabular}{|c|c|c|c|}
\hline Variable & $\begin{array}{c}\text { ND } \\
\left(\begin{array}{l}N=164) \\
\end{array}\right.\end{array}$ & $\begin{array}{c}\text { 22q11.2DS } \\
(\mathrm{N}=44)\end{array}$ & $P$ value \\
\hline \multicolumn{4}{|l|}{ Gender } \\
\hline Female & $65(40)$ & $20(46)$ & .30 \\
\hline Male & $99(60)$ & $24(54)$ & \\
\hline \multicolumn{4}{|l|}{ Race } \\
\hline White & $128(78)$ & $30(68)$ & .18 \\
\hline African American & $22(13)$ & $6(14)$ & \\
\hline Other & $14(9)$ & $8(18)$ & \\
\hline \multicolumn{4}{|l|}{ Gestational age* } \\
\hline Full term & $128(78)$ & $36(82)$ & .29 \\
\hline Premature & $33(20)$ & $6(14)$ & \\
\hline Unknown & $3(2)$ & $2(4)$ & \\
\hline \multicolumn{4}{|l|}{ Timing of TOF diagnosis } \\
\hline Prenatal & $41(25)$ & $13(30)$ & .56 \\
\hline Postnatal & $119(73)$ & $29(66)$ & \\
\hline Unknown & $4(2)$ & $2(4)$ & \\
\hline Age at surgery, mo & $3(0.5-5.3)$ & $3.9(1.6-6.8)$ & .13 \\
\hline Neonatal repair $(<1 \mathrm{mo})$ & $47(29)$ & $9(20)$ & .34 \\
\hline Weight on admission $(\mathrm{kg})$ & $5.1( \pm 1.9)$ & $5.0( \pm 1.6)$ & .91 \\
\hline \multicolumn{4}{|l|}{ Pulmonary valve anatomy } \\
\hline Stenosis & $108(66)$ & $26(59)$ & .70 \\
\hline Atresia & $42(25)$ & $14(32)$ & \\
\hline Absent & $13(8)$ & $4(9)$ & \\
\hline Atrioventricular canal & $1(1)$ & $0(0)$ & \\
\hline Shunt-pre $\dagger$ & $13(7)$ & $9(21)$ & .03 \\
\hline \multicolumn{4}{|l|}{ Surgical repair } \\
\hline VSD closure alone & $20(12)$ & $1(2)$ & .20 \\
\hline Nontransannular patch & $13(8)$ & $5(11)$ & \\
\hline Transannular patch & $101(62)$ & $24(55)$ & \\
\hline RV-PA conduit & $30(18)$ & $14(32)$ & \\
\hline
\end{tabular}

Data are expressed as mean ( \pm standard deviation), median (interquartile range), or frequency (percentage). $N D$, Nondeleted; 22q11.2DS, 22q11.2 deletion syndrome; $V S D$, ventricular septal defect; $R V-P A$, right ventricle to pulmonary artery; $T O F$, tetralogy of Fallot. *Prematurity is defined as gestational age less than 37 weeks. $\dagger$ Shunt-pre refers to placement of aortopulmonary shunt before complete surgical repair.

There were important differences between the 2 groups. Patients with 22q11.2DS more commonly received an aortopulmonary shunt preceding complete surgical repair (9/44 [21\%] compared with $13 / 164$ [7\%] in the ND group, $P=.03)$. This association remained significant after adjusting for pulmonary valve status, gestational age, birth weight, admission weight, age at surgical repair, extracardiac malformations, and era of surgical repair. Moreover, the patients with 22q11.2DS had longer duration of CPB $(84 \pm 31$ minutes vs $74 \pm 30$ minutes, $P=.02)$. This association persisted after adjusting for previous shunt placement and presenting pulmonary valve status. Overall length of intensive care was longer for the 22q11.2DS group (6 days [4-12] vs 4 days [3-8] in the ND group, $P=.007$ ) (Table 2). CPB was a confounder of the association of deletion status and length of intensive care, although CPB was not an independent predictor of length of intensive care. Although most of the ND group had no consultations by other
TABLE 2. Outcomes according to 22q11.2 deletion syndrome status

\begin{tabular}{|c|c|c|c|}
\hline Variable & $\begin{array}{c}\text { ND } \\
(\mathbf{N}=164)\end{array}$ & $\begin{array}{l}\text { 22q11.2DS } \\
(\mathrm{N}=44)\end{array}$ & $P$ value \\
\hline \multicolumn{4}{|l|}{ Outcome } \\
\hline Death & $3(2)$ & $1(2)$ & .9 \\
\hline Discharge & $148(90)$ & $39(89)$ & \\
\hline Other* & $13(8)$ & $4(9)$ & \\
\hline Length of stay, $\mathrm{d} \dagger$ & $6(4-13)$ & $9(6-16)$ & .053 \\
\hline Length of stay if discharged, $\mathrm{d}$ & $6.0(4-11)$ & $9.0(5-15)$ & .02 \\
\hline Hospital stay $>4 \mathrm{wk}$ & $9(5)$ & $2(5)$ & 1.00 \\
\hline Intensive care, $\mathrm{d}$ & $4(3-7)$ & $6(4-12)$ & .007 \\
\hline $\mathrm{CPB}, \min$ & $74( \pm 30)$ & $84( \pm 31)$ & .02 \\
\hline $\begin{array}{l}\text { Deep hypothermic circulatory } \\
\text { arrest, min }\end{array}$ & $15.3( \pm 20)$ & $20.8( \pm 23)$ & .06 \\
\hline Ventilation, $\mathrm{h}$ & $25.4(10-74)$ & $32(23-90)$ & .09 \\
\hline \multicolumn{4}{|l|}{ Resource use } \\
\hline \multicolumn{4}{|l|}{ No. of consultations } \\
\hline 0 & $125(76)$ & $22(50)$ & .001 \\
\hline 1 & $20(12)$ & $7(16)$ & \\
\hline$\geq 2$ & $19(12)$ & $15(34)$ & \\
\hline \multicolumn{4}{|l|}{ Complications } \\
\hline Infections & $11(7)$ & $6(14)$ & .21 \\
\hline Pericardial effusion & $7(4)$ & $1(2)$ & 1.00 \\
\hline Junctional ectopic tachycardia & $13(8)$ & $1(2)$ & .31 \\
\hline Catheterizations & $31(19)$ & $13(30)$ & .15 \\
\hline Reoperations & $15(9)$ & $4(9)$ & .85 \\
\hline $\begin{array}{l}\text { Extracorporeal membrane } \\
\text { oxygenation }\end{array}$ & $1(0.6)$ & & 1.00 \\
\hline Cardiac arrest & $5(3)$ & $1(2.3)$ & 1.00 \\
\hline $\begin{array}{l}\text { Discharge characteristics } \ddagger \\
\text { Feeding }\end{array}$ & $\mathrm{N}=161$ & $\mathrm{~N}=43$ & \\
\hline Nasogastric + oral & $24(15)$ & $11(26)$ & .11 \\
\hline Oral & $137(85)$ & $32(74)$ & \\
\hline No. of medications & $2(1-3)$ & $3(2-5)$ & .0001 \\
\hline
\end{tabular}

Data are expressed as mean ( \pm standard deviation), median (interquartile range), or number (percentage). $N D$, Nondeleted; 22q11.2DS, 22q11.2 deletion syndrome; $C P B$, cardiopulmonary bypass. *Discharged to another hospital or chronic care facility. †Length of stay for the whole cohort. $\ddagger$ Includes survivors only.

subspecialties, $50 \%$ of the $22 \mathrm{q} 11.2 \mathrm{DS}$ group had consultations, of whom $25 \%$ had more than 2 consultations during the hospital stay $(P=.001)$. Finally, the 22q11.2DS group was discharged with more medications compared with the ND group (3 [2-5] vs 2 [1-3], $P=.001)$.

\section{DISCUSSION}

Our study identifies important differences in perioperative outcomes between subjects with 22q11.2DS and ND subjects with TOF. Patients with 22q11.2DS were observed to have more palliative procedures, longer $\mathrm{CPB}$, longer duration of intensive care, and more resource use in terms of consultations by other subspecialties. Potential causes for increased intensive care in the 22q11.2DS population could be their tendency toward airway difficulties and need for increased respiratory support. ${ }^{10}$ However, mechanical ventilation was comparable in the 2 groups; thus, it is unlikely that intensive care was prolonged on account of the duration 
of mechanical ventilation. Therefore, other factors must have contributed to longer intensive care duration. Of note, patients with 22q11.2DS did not have more infections than ND patients; therefore, infections were not likely to contribute to the increased length of intensive care.

We found that patients with 22q11.2DS had longer duration of $\mathrm{CPB}$. Although not substantially different clinically, this difference could in itself be associated with a longer duration of intensive care because of a greater systemic inflammatory response and resultant postoperative edema and end-organ dysfunction. Allan and colleagues ${ }^{11}$ found a positive correlation between interleukin production and duration of CPB, longer intubation times, and intensive care stay. However, the reason that deletion status is associated with longer CPB is unclear, and the retrospective nature of our study did not allow for its determination.

Effect of genotype on surgical outcome, specifically the renin-angiotensin-aldosterone system genotype, has been linked to other groups of congenital heart disease. ${ }^{12}$ Thus, 22q11.2DS could likewise contribute to surgical outcome, given that 22q11.2DS can affect genes that are involved not only in the septation of the conotruncus but also in RV structure, thus perhaps contributing to RV function and adaptation to surgical stress. ${ }^{13,14}$ Alternatively, 22q11.2DS might contribute to postoperative RV restrictive physiology in TOF. ${ }^{15}$

Placement of an aortopulmonary shunt was more commonly performed in patients with 22q11.2DS, independently of gestational age, pulmonary valve status, age at surgical repair, and extracardiac malformations. Once again, the retrospective nature of our study limits our ability to discern specific factors that resulted in this management plan. Moreover, it was not possible to ascertain from chart review whether deletion status was known to the caretakers before the surgical planning. Therefore, the knowledge of deletion status may have affected the decision to perform a shunt. Additional malformations might influence surgical planning, as suggested by Michielon and colleagues. ${ }^{16}$ However, in our study the 22q11.2DS population did not have more major anomalies than the ND subset, and thus the difference in management strategy cannot be ascribed to the presence of noncardiac anomalies. Although placement of an aortopulmonary shunt does not seem to affect survival after complete repair for TOF, it may increase the risk for pulmonary artery distortion, which has the potential to prolong perioperative recovery and hospitalization. ${ }^{17}$ Thus, a prior aortopulmonary shunt indirectly has the potential to add morbidity and increase costs. ${ }^{18,19}$

A prolonged hospitalization and longer period of intensive care support in patients with 22q11.2DS may have significant clinical implications. As a result of the deletion, children with 22q11.2DS already have developmental delays, hypotonia, and speech problems that seem to be independent
TABLE 3. Extracardiac malformations according to $22 q 11.2$ deletion syndrome status

\begin{tabular}{lccc}
\hline & ND & $\mathbf{2 2 q 1 1 . 2 D S}$ & \\
& $(\mathbf{N}=\mathbf{1 6 4})$ & $(\mathbf{N}=\mathbf{4 4})$ & $\boldsymbol{P}$ value \\
\hline Dysmorphic facies & $43(26)$ & $37(84)$ & $<.001$ \\
Head & $8(5)$ & $2(5)$ & .95 \\
Eye & $6(4)$ & $4(9)$ & .13 \\
Ear & $16(10)$ & $17(39)$ & $<.001$ \\
Nose & $8(5)$ & $17(39)$ & $<.001$ \\
Mouth & $6(4)$ & $10(23)$ & .001 \\
Palate* & $8(5)$ & $12(27)$ & $<.001$ \\
Airway $\dagger$ & $7(4)$ & $4(9)$ & .23 \\
Abdominal $\ddagger$ & $6(4)$ & $2(4.5)$ & .92 \\
Renal $\S$ & $6(4)$ & $2(5)$ & .98 \\
Genital $\|$ & $10(6)$ & $2(5)$ & .61 \\
Skeletal & $17(10)$ & $11(25)$ & .03 \\
Hand & $23(14)$ & $18(41)$ & $<.001$ \\
\hline Dat & &
\end{tabular}

Data are expressed as number (percent). $N D$, Nondeleted; 22q11.2DS, 22q11.2 deletion syndrome. *Cleft lip/palate, submucous cleft, bifid uvula, high arched palate, and velopharyngeal incompetence. $\nmid$ Laryngo-bronchio-tracheomalacia, tracheal stenosis, subglottic stenosis, choanal stenosis or atresia, tracheal web, tracheoesophageal fistula. †̣Intestinal malrotation, omphalocele, umbilical/inguinal hernia, pyloric stenosis, polysplenia. §Horseshoe, cystic, dysplastic, and single kidney; hydronephrosis; ureteral abnormalities. ||Ambiguous genitalia, hypospadias, undescended testes, imperforate anus, anteriorly placed anus. $\uparrow$ Hemi and butterfly vertebrae, fused ribs, short limbs, scoliosis, winged scapula, sacral dimple, tethered cord.

of the cardiac disease. ${ }^{20}$ Evidence also suggests that the length of the postoperative hospitalization for congenital heart disease affects later neurodevelopment outcomes independently of genetic syndromes and other factors, such as demographic and socioeconomic status, perioperative complications, and CPB times. ${ }^{21,22}$ Such evidence stresses the need for focused management, especially in patients with genetic syndromes, to accomplish a shorter hospital stay, and thereby optimize neurocognitive outcomes.

Major extracardiac anomalies were present in both groups, and significant differences were found in organs that are typically involved with greater frequency in patients with 22q11.2DS: anomalies of the ears, nose, mouth, palate, and hand, most of which describe minor facial features rather than major anomalies expected to confer a clinical difference. We also found skeletal anomalies to be more common in the 22q11.2DS group (Table 3). Other studies found 22q11.2DS and ND subjects to be comparable in terms of major organ system anomalies, such as airway, gastrointestinal, genital, renal, and central nervous system..$^{23,24}$ Therefore, although dysmorphisms are common in patients with 22q11.2DS, major extracardiac malformations were not more common in the TOF group when compared with those without 22q11.2DS.

Our study also describes important similarities between patients with TOF with and without 22q11.2DS. We found that overall patient characteristics, presenting anatomy, complications, reoperations, major congenital anomalies, and survival were comparable between the 2 groups. Of note, feeding problems were not more common in the 
22q11.2DS group, a pertinent finding in light of the common assumption that patients with 22q11.2DS have more feeding difficulties. All of these findings are important and highlight the fact that 22q11.2DS results in increased morbidity, rather than mortality, in this particular patient population. $^{8,9,25}$ The same may not be true in the more complicated cohort with major aortopulmonary collateral arteries requiring staged repairs, as suggested by Mahle and colleagues. ${ }^{7}$

Our results suggest that patients with 22q11.2DS require more resource use as reflected by the increased number of consulting services. These consultations likely provide appropriate routing of the patient with 22q11.2DS to the various specialties needed in their follow-up.

\section{Study Limitations}

The retrospective nature of this study limits our ability to further detail differences between the patients with and without 22q11.2DS, including the ability to ascertain whether the patient was recognized clinically to have DiGeorge syndrome or whether deletion status was known to the caretakers before surgical planning. Such knowledge might have biased caretakers toward placement of an aortopulmonary shunt preceding a complete repair in the 22q11.2DS group.

We opted not to examine echocardiographic variables (eg, the size of the pulmonary arteries) because of the inconsistency associated with retrospective data collection. Nonetheless, we were able to study a large number of patients with TOF who underwent operation at a single institution. In addition, because we included only subjects with a complete repair preceded or not by an aortopulmonary shunt, we were able to study a relatively homogeneous population in terms of cardiac phenotype and surgery. Therefore, these results likely apply to patients with TOF with anatomy favorable for this type of surgical approach.

\section{CONCLUSIONS}

This study examined a large group of patients with TOF who underwent operation at a single institution and reports outcomes in the subset undergoing complete surgical repair. We found that although outcomes are comparable in many respects, patients with TOF and 22q11.2DS are at risk for longer postoperative recovery, suggesting that postoperative management may need to be tailored to the patient with $22 \mathrm{q} 11.2 \mathrm{DS}$. This finding is particularly important given the evidence for worse cognitive outcomes associated with longer hospital stays. Also noteworthy was the encouraging finding that the 22q11.2DS group had a similar survival as the ND group.

In the era of prenatal diagnosis and tailored patient care, genetic stratification is important and should be considered when counseling parents, planning surgical procedures, and determining postoperative management strategies in patients with TOF. Future studies should target the perioperative period to identify modifiable factors to improve outcomes.

The authors thank Sharon M. Edman, MS, for extensive work in data organization and management.

\section{References}

1. Perry LW, Neill CA, Ferencz C, Rubin JD, Loffredo CA. Infants with Congenital Heart Disease: The Cases. Mount Kisco, NY: Futura Publishing Company, Inc; 1993.

2. Trainer AH, Morrison N, Dunlop A, Wilson N, Tolmie J. Chromosome 22q11 microdeletions in tetralogy of Fallot. Arch Dis Child. 1996;74:62-3.

3. Takahashi K, Kido S, Hoshino K, Ogawa K, Ohashi H, Fukushima Y. Frequency of a 22q11 deletion in patients with conotruncal cardiac malformations: a prospective study. Eur J Pediatr. 1995;154:878-81.

4. Amati F, Mari A, Digilio MC, Mingarelli R, Marino B, Giannotti A, et al. 22q11 deletions in isolated and syndromic patients with tetralogy of Fallot. Hum Genet. 1995;95:479-82.

5. Goldmuntz E, Clark BJ, Mitchell LE, Jawad AF, Cuneo BF, Reed L, et al. Frequency of 22q11 deletions in patients with conotruncal defects. J Am Coll Cardiol. 1998;32:492-8.

6. Goldmuntz E, Driscoll D, Budarf ML, Zackai EH, McDonald-McGinn DM, Biegel JA, et al. Microdeletions of chromosomal region 22q11 in patients with congenital conotruncal cardiac defects. J Med Genet. 1993; 30:807-12.

7. Mahle WT, Crisalli J, Coleman K, Campbell RM, Tam VK, Vincent RN, et al. Deletion of chromosome 22q11.2 and outcome in patients with pulmonary atresia and ventricular septal defect. Ann Thorac Surg. 2003; 76:567-71.

8. van Dongen EI, Glansdorp AG, Mildner RJ, McCrindle BW, Sakopoulos AG, VanArsdell G, et al. The influence of perioperative factors on outcomes in children aged less than 18 months after repair of tetralogy of Fallot. J Thorac Cardiovasc Surg. 2003;126:703-10.

9. Doell C, Bernet V, Molinari L, Beck I, Balmer C, Latal B. Children with genetic disorders undergoing open-heart surgery: are they at increased risk for postoperative complications? Pediatr Crit Care Med. 2011;12:539-44.

10. Kyburz A, Bauersfeld U, Schinzel A, Riegel M, Hug M, Tomaske M, et al. The fate of children with microdeletion 22q11.2 syndrome and congenital heart defect: clinical course and cardiac outcome. Pediatr Cardiol. 2008;29: 76-83.

11. Allan CK, Newburger JW, McGrath E, Elder J, Psoinos C, Laussen PC, et al. The relationship between inflammatory activation and clinical outcome after infant cardiopulmonary bypass. Anesth Analg. 2010;111:1244-51.

12. Mital S, Chung WK, Colan SD, Sleeper LA, Manlhiot C, Arrington CB, et al. Renin-angiotensin-aldosterone genotype influences ventricular remodeling in infants with single ventricle. Circulation. 2011;123:2353-62.

13. Restivo A, Piacentini G, Placidi S, Saffirio C, Marino B. Cardiac outflow tract: a review of some embryogenetic aspects of the conotruncal region of the heart. Anat Rec A Discov Mol Cell Evol Biol. 2006;288:936-43.

14. Restivo A, Sarkozy A, Digilio MC, Dallapiccola B, Marino B. 22q11 deletion syndrome: a review of some developmental biology aspects of the cardiovascular system. J Cardiovasc Med (Hagerstown). 2006;7:77-85.

15. Cullen S, Shore D, Redington A. Characterization of right ventricular diastolic performance after complete repair of tetralogy of Fallot. Restrictive physiology predicts slow postoperative recovery. Circulation. 1995;91:1782-9.

16. Michielon G, Marino B, Formigari R, Gargiulo G, Picchio F, Digilio MC, et al. Genetic syndromes and outcome after surgical correction of tetralogy of Fallot. Ann Thorac Surg. 2006;81:968-75.

17. Seddio F, Migliazza L, Borghi A, Crupi G. Previous palliation in patients with tetralogy of Fallot does not influence the outcome of later repair. J Cardiovasc Med (Hagerstown). 2007;8:119-22.

18. Gladman G, McCrindle BW, Williams WG, Freedom RM, Benson LN. The modified Blalock-Taussig shunt: clinical impact and morbidity in Fallot's tetralogy in the current era. J Thorac Cardiovasc Surg. 1997;114:25-30.

19. Ungerleider RM, Kanter RJ, O'Laughlin M, Bengur AR, Anderson PA, Herlong JR, et al. Effect of repair strategy on hospital cost for infants with tetralogy of Fallot. Ann Surg. 1997;225:779-84. 
20. Gerdes M, Solot C, Wang PP, Moss E, LaRossa D, Randall P, et al. Cognitive and behavior profile of preschool children with chromosome 22q11.2 deletion. Am J Med Genet. 1999;85:127-33.

21. Gaynor JW, Wernovsky G, Jarvik GP, Bernbaum J, Gerdes M, Zackai E, et al. Patient characteristics are important determinants of neurodevelopmental outcome at one year of age after neonatal and infant cardiac surgery. J Thorac Cardiovasc Surg. 2007;133:1344-53, 1353.e1-3.

22. Limperopoulos C, Majnemer A, Shevell MI, Rohlicek C, Rosenblatt B, Tchervenkov C, et al. Predictors of developmental disabilities after open heart surgery in young children with congenital heart defects. J Pediatr. 2002;141:51-8.
23. Rauch R, Hofbeck M, Zweier C, Koch A, Zink S, Trautmann U, et al. Comprehensive genotype-phenotype analysis in 230 patients with tetralogy of Fallot. $J$ Med Genet. 2010;47:321-31.

24. Piran S, Bassett AS, Grewal J, Swaby JA, Morel C, Oechslin EN, et al. Patterns of cardiac and extracardiac anomalies in adults with tetralogy of Fallot. Am Heart J. 2011;161:131-7.

25. Michielon G, Marino B, Oricchio G, Digilio MC, Iorio F, Filippelli S, et al. Impact of del22q11, trisomy 21 , and other genetic syndromes on surgical outcome of conotruncal heart defects. J Thorac Cardiovasc Surg. 2009;138: 565-70.e2. 